\title{
Malformed Teeth and Their Endodontic Implications
}

\author{
Annapoorna1 ${ }^{1}$ Manjunatha M.2 ${ }^{2}$ Shubhashini N. ${ }^{3}$, Swetha H. B. ${ }^{4}$
}

${ }^{1}$ Department of Conservative Dentistry and Endodontics Rajarajeswari Dental College and Hospital, Bengaluru, Karnataka, India. ${ }^{2}$ Department of Conservative Dentistry and Endodontics, Shyamala Reddy Dental College and Hospital, Bengaluru, Karnataka, India. ${ }^{3}$ Department of Conservative Dentistry and Endodontics, Rajarajeswari Dental

College and Hospital, Bengaluru, Karnataka, India. ${ }^{4}$ Department of Conservative Dentistry and Endodontics, Rajarajeswari Dental College and Hospital, Bengaluru, Karnataka, India.

\section{INTRODUCTION}

Increased dimension of a tooth indicates the presence of double tooth. Double tooth could be due to fusion or gemination. These are due to developmental disturbances of teeth. ${ }^{1}$ Gemination is an anomaly that occurs due to an attempt to form two teeth from a single tooth bud. This resulted in a large tooth without complete separation or alterations in the number of teeth. ${ }^{2}$ Fusion is caused by union of two discrete tooth germs, wherein they might be united by dental hard tissues. However they have separate pulp chambers. Developmental aberrations occur during morphodifferentiation of tooth bud. These occur due to local metabolic disturbances or due to pressure of crowding of tooth germs. ${ }^{3}$ Hereditary tendency has been reported for fusion between normal and supernumerary tooth. ${ }^{4}$ Complex internal anatomy of double teeth have clinical significance and thorough knowledge of root canal anatomy is required before starting treatment in an endodontically involved tooth. ${ }^{5}$ Anomalous variations of teeth in humans are found, which can involve only the crown and/or root of teeth. Extra cusps pose difficulties in dental hygiene maintenance which can lead to dental caries and its complications. This paper presents an uncommon finding of bolk cusp or paramolar tubercle. In this case the tooth was pulpally involved and needed an endodontic intervention.

\section{PRESENTATION OF CASE}

A 25-year-old female patient reported to Prabha Dental clinic, Bangalore, with pain in her upper right back tooth region since 1 week. Pain was continuous which got aggravated during eating.

On clinical examination, supernumerary cusp was seen on buccal aspect of maxillary second premolar in the first quadrant. The tooth was tender to percussion. Clinically caries was not visible. An intra-oral periapical radiograph was taken of the tooth that revealed caries on the mesial aspect of the tooth encroaching the pulpal space. No periapical radiolucency was seen. A cone beam computer tomography of the tooth was advised to evaluate the root canal morphology and to identify for the presence of canal associated with parastyle cusp.

CBCT report showed prescence of three canals- mesiobuccal, distobuccal and palatal canal. No additional root canal was present. Hence it was diagnosed as an additional cusp without presence of extra root or a canal.

\author{
Corresponding Author: \\ Dr. Annapoorna, \\ Prabha Dental Clinic, \\ Shop no 6, Ground floor, \\ 10th Main, Hanumanthanagara \\ Bengaluru-560050, Karnataka, India. \\ E-mail: kinimai@gmail.com
}

DOI: $10.14260 /$ jemds/2020/55

Financial or Other Competing Interests: None.

How to Cite This Article:

Annapoorna, Manjunatha M, Shubhashini

$N$, et al. Malformed teeth and their endodontic implications. J. Evolution Med. Dent. Sci. 2020;9(04):245-247, DOI: 10.14260/jemds/2020/55

Submission 22-10-2019,

Peer Review 08-01-2019,

Acceptance 14-01-2020,

Published 27-01-2020. 
CLINICAL DIAGNOSIS

Supernumerary cusp on mesiobuccal aspect of maxillary second molar. Acute irreversible pulpitis (pulpal diagnosis).

\section{DIFFERENTIAL DIAGNOSIS}

1. Gemination.

2. Fusion.

\section{DEFINITIVE DIAGNOSIS}

Acute irreversible pulpitis of maxillary second molar with parastyle cusp.

\section{DISCUSSION OF MANAGEMENT}

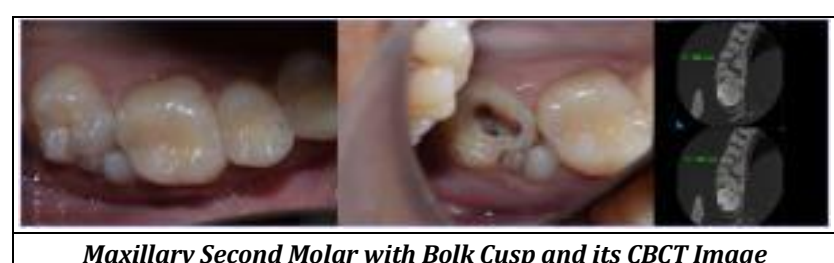

Maxillary Second Molar with Bolk Cusp and its CBCT Image

Root canal treatment of the tooth was done. Local anaesthesia (lidocaine 2\%) was administered to the patient. Access opening was done with endo access bur. After caries excavation, the missing mesial wall was built using composite resin. Three orifices were found, and three canals were negotiated. The three canals were mesiobuccal, distobuccal and palatal. Working length of the tooth was measured using apex locater (Root ZX, J Morita) and radiographic method. Cleaning and shaping of the root canals were done using rotary Pro Taper files. Obturation was done using single cone obturation technique, using $6 \%$ gutta-percha technique. Access was restored using composite resin. After 5 days of the treatment the tooth was restored and reinforced using metal crown.

\section{DISCUSSION}

Fundamental prerequisite for success of root canal treatment is knowledge about morphological variations of tooth. High variations in the morphology of teeth is seen in primary and permanent dentitions. Variations are seen as an accessory cusp or increase in the number of roots and root canals. These variations may be due to the abnormalities during differentiation of dental lamina and tooth germ. Dental anomalies of number and forms occur. The occurrence of these anomalies is seen to be less than $1 \%$ and the percentage of occurrence is even less in posterior teeth. ${ }^{6}$ Hence management of these cases require careful radiographic and cone beam computer topographic analysis for proper treatment and to prevent possible complications. These tools help in proper assessment and revel the complexity of the root canal. ${ }^{7}$

Double tooth is a developmental anomaly wherein two teeth appear to be joined. They could be fusion, gemination or twinning. Gemination is defined as formation of equivalent of two teeth from the same follicle, with evidence of an attempt for teeth to be completely separate. This occurs due to the invagination of developing dental organ. Clinically it is presented as a groove or depression which delineates two teeth. ${ }^{8}$ Fusion is defined as the union between dentin and enamel of two or more separate developing teeth. Fusion occurs during morphodifferentiation stage of tooth development. Fusion can occur between normal teeth or between normal and supernumerary tooth. Fusion is seen in $0.6 \%$ of primary dentition and $0.1 \%$ of permanent dentition. ${ }^{9}$ An accessory cusp on buccal surface of maxillary molars are termed as parastyle or paramolar tubercle. 10 it is considered as cingulum derivative seen usually seen on the paracone and rarely seen on the metacone of buccal surface of maxillary molars. These upper paramolar complexes were found in $0.4 \%-2.8 \%$ of the cases. ${ }^{10,11}$

Morpho-anatomic changes are generally asymptomatic. These could lead to problems like aesthetics, periodontal destruction and carious destruction leading to pulpal necrosis. Thorough cleaning and shaping of the root canals with three dimensional obturation of the canal system is a prerequisite for success of endodontics treatment. Anatomic variations of double teeth makes cleaning and shaping difficult. Although in these cases use of current diagnostic method, magnification and thorough chemo-mechanical preparation aided in endodontic success. These characteristics of teeth should be identified and recorded for clinical and forensic uses. 5

\section{CONCLUSIONS}

Documentation of morphologic anomalies of the teeth aids in increasing the awareness of identification, early detection and early management of rare entities. This helps in early detection, effective management and prevention of complications by the dental practitioners.

\section{REFERENCES}

[1] Yagci A, Cantekin K, Buyuk SK, et al. The multidisciplinary management of fused maxillary lateral incisor with a supernumerary tooth in cleft lip adolescence. Article ID 459416, Case Rep Dent 2014;2014:1-5.

[2] Flares BF, Denise PL, Bruno MC, et al. The challenges of treating a fused tooth. Braz Dent J 2012;23(3):256-62.

[3] Kyu-Min C, Ji-Hyun J, Sang-Hyuk P. Clinical management of a fused upper premolar with supernumerary tooth: a case report. Restor Dent Endod 2014;39(4):319-23.

[4] Good DL, Berson RB. A supernumerary tooth fused to a maxillary permanent central incisor. Pediatr Dent 1980;2(4):294-6.

[5] Saeed A. Endodontic treatment of a maxillary second molar with developmental anomaly: a case report. Iran Endod J 2007;2(2):73-6.

[6] Tsesis I, Steinbock N, Rosenberg E, et al. Endodontic treatment of developmental anomalies in posterior teeth: treatment of geminated/fused teeth- report of two cases. Int Endod J 2003;36(5):372-9. 
[7] Gauri SL, Hiral BG. Conjoined permanent maxillary posterior teeth: a rare anomaly. Int J Oral Health and Med Res 2015;2(4):55-7.

[8] Avinash AP, Sanjana AP, Preeti KD. Endodontic management of a supernumerary tooth fused to the maxillary permanent lateral incisor. Saudi Endod J 2014;4(1):28-31.
[9] Sandhya S, Manisha T, Shweta S. Fusion/double teeth. J of Ind Acad of Oral Med \& Radiol 2011;23(3):468-70.

[10] Zoya C, Disha G, Ranjana M, et al. Parastyle cusp: a rare morphologic variant of maxillary second molars. J Forensic Dent Sci 2018;10(2):111-5.

[11] Shivani S, Sumit T, Vimal K. Paramolar tubercle-Bolkcusp: a case report. J Oral Res Rev 2018;10(2):76-9. 